\title{
EL SOMONTANO: UN VIÑEDO EN CONSTRUCCIÓN
}

\author{
Cazenave-Piarrot, $\mathrm{A}$. \\ Maître de Conférences à I'IUFM de Toulouse. alain.cazenave-piarrot@wanadoo.fr
}

Resumen: El viñedo del Somontano en Aragón se ha desarrollado recientemente, después de la obtención de una "denominación de origen" en 1984. El Somontano cubre, aproximadamente 3000 ha, la producción, en alza•regular, es de 100.667 hectólitros en 2002. Se trata de hecho de un vinedo nuevo que se construye en una vieja región vitícola. La nueva viticultura se desarrolla según tres ejes: diversificación de cepas, enologización y sobre todo política comercial dinámica. Las casas comerciales están dominadas por tres grandes bodegas -Viñas del Vero, Pirineos, Enate- con participaciones cruzadas, que pertenecen mayoritariamente a empresas privadas, aunque el Gobierno de Aragón posee también participaciones. La promoción del viñedo se apoya en la utilización de la historia del alto Aragón, se reclama de la antigua tradición vitícola y utiliza como referente identitario la geografia, en particular la montaña, que sirve de encuadre a los nuevos paisajes vitícolas. Este viñedo es también un medio de afirmar el dinamismo de la economía aragonesa y más ampliamente de la "movida", movimiento que acompaña al despegue y a las mutaciones de la sociedad española desde hace veinte años.

Palabras clave: medio rural, áreas vitivinícolas, Aragón, agroindustria.

\begin{abstract}
The vineyard of Somontano in Aragon has expanded recently, after obtaining an AOC label in 1984. It stretches over about 3,000 ha, and its constantly rising production reached 100,667 hectolitres in 2002. It is actually a new vineyard set up in an old wine-producing area. This new wine-growing activity follows three main lines: a diversification of grape varieties, an oenological policy and, above all, a dynamic marketing. The business is dominated by three leading bodegas -Viñas de Vero, Pirineos, Enate- with a reciprocal shareholding, mainly owned by private bosses, even if some the shares are held by the Government of Aragon. The promotion of this vineyard had been based on the culture of Upper Aragon, vindicating an old wine-growing tradition and using the geographical situation as a distinctive referent, especially the mountain which serves as a background to the new wine-growing landscapes. This vineyard is also a way of asserting the dynamism of economy in Aragon, and, even more broadly, of the movida, the movement that has been associated with the take-off and social changes in Spain for the last two decades.
\end{abstract}

Keywords: countryside, wine-growing areas, Aragon, agro-industry. 


\section{Introducción}

El viñedo del Somontano se sitúa en la provincia de Huesca, en Aragón, y constituye una nueva denominación de origen en el conjunto vitivinícola español. Dicha denominación reune 43 municipios, ubicados los más en la comarca natural del Somontano de Barbastro y cubre en total 205.000 hectáreas. Pero, de éstas, tan sólo 2.903 ha de viñedo tienen derecho a la denominación de origen Somontano, lo que indica cuán débil es su huella en el paisaje, con excepción del complejo vitivinícola que agrupa, en un radio de unos pocos kilómetros al norte de Barbastro, a las principales bodegas de vinificación y la mayor parte de los viñedos así nombrados.

Se trata de un viñedo joven, ya que el primer decreto de aplicación se remonta apenas 20 años atrás (octubre de 1984), en un mundo de arraigadas estructuras como es el vitivinícola. La producción que despegó un nivel muy bajo, por cierto, se disparó, pasando de 13.335 hectólitros (hl) en 1990 a 103.141 en 2000 y 100.667 en 2002, mientras que la comercialización alcanzaba en 1999-2000 a 70.220 hl, contra 3.863 en la vendimia de 1989-1999.

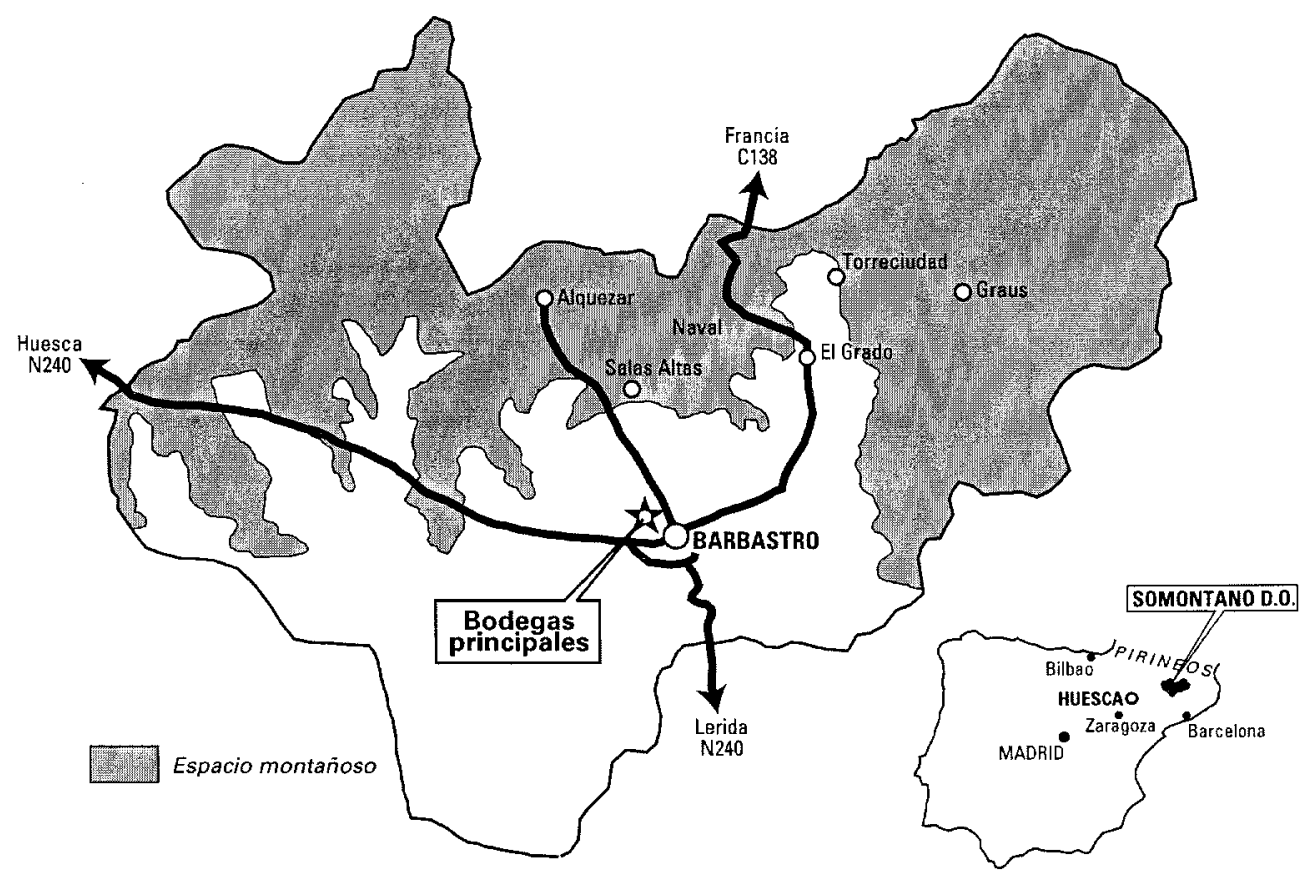

Figura 1. La denominación de origen Somontano. 
Producción de uvas blancas y tintas (datos en quintales métricos)

\begin{tabular}{|c|c|c|c|c|c|c|c|c|c|c|}
\hline AÑOS & 1994 & 1995 & 1996 & 1997 & 1998 & 1999 & $\mathbf{2 0 0 0}$ & $\mathbf{2 0 0 1}$ & 2002 & 2003 \\
\hline Uva blanca & 14.574 & 22.015 & 27.760 & 27.886 & 24.763 & 18.305 & 29.370 & 24.033 & 21.790 & 26.652 \\
\hline Uya tinta & 48.081 & 63.955 & 85.070 & 88.148 & 76.176 & 79.640 & 116.155 & 95.839 & 125.901 & 170.033 \\
\hline TOTAL & $\mathbf{6 2 . 6 5 5}$ & $\mathbf{8 5 . 9 7 0}$ & $\mathbf{1 1 2 . 8 3 0}$ & $\mathbf{1 1 6 . 0 3 4}$ & $\mathbf{1 0 0 . 9 3 9}$ & 97.945 & $\mathbf{1 4 5 . 5 2 5}$ & $\mathbf{1 1 9 . 8 7 2}$ & $\mathbf{1 4 7 . 6 9 1}$ & $\mathbf{1 9 6 . 6 8 5}$ \\
\hline
\end{tabular}

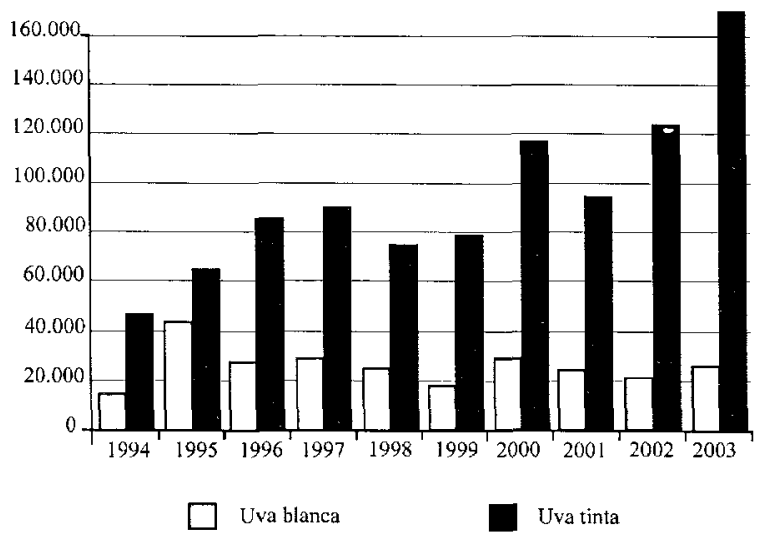

Producción de vino de Denominación de Origen (datos en hectolitros)

\begin{tabular}{|c|c|c|c|c|c|c|c|c|c|c|}
\hline A NOS & $\mathbf{1 9 9 3}$ & 1994 & 1995 & $\mathbf{1 9 9 6}$ & 1997 & $\mathbf{1 9 9 8}$ & $\mathbf{1 9 9 9}$ & $\mathbf{2 0 0 0}$ & 2001 & 2002 \\
\hline $\begin{array}{c}\text { Vino } \\
\text { blanco }\end{array}$ & 8.467 & 7.712 & 11.201 & 16.066 & 16.804 & 16.833 & 12.459 & 18.427 & 16.146 & 14.623 \\
\hline $\begin{array}{c}\text { Vino tinto } \\
\text { y rosado }\end{array}$ & 24.077 & 26.905 & 35.492 & 57.411 & 64.805 & 54.325 & 57.160 & 84.714 & 68.137 & 86.044 \\
\hline TOTAL & $\mathbf{3 2 . 5 4 4}$ & $\mathbf{3 4 . 6 1 7}$ & $\mathbf{4 6 . 6 9 3}$ & $\mathbf{7 3 . 4 7 7}$ & $\mathbf{8 1 . 6 0 9}$ & $\mathbf{7 1 . 1 5 8}$ & $\mathbf{6 9 . 6 1 9}$ & $\mathbf{1 0 3 . 1 4 1}$ & $\mathbf{8 4 . 2 8 3}$ & $\mathbf{1 0 0 . 6 6 7}$ \\
\hline
\end{tabular}

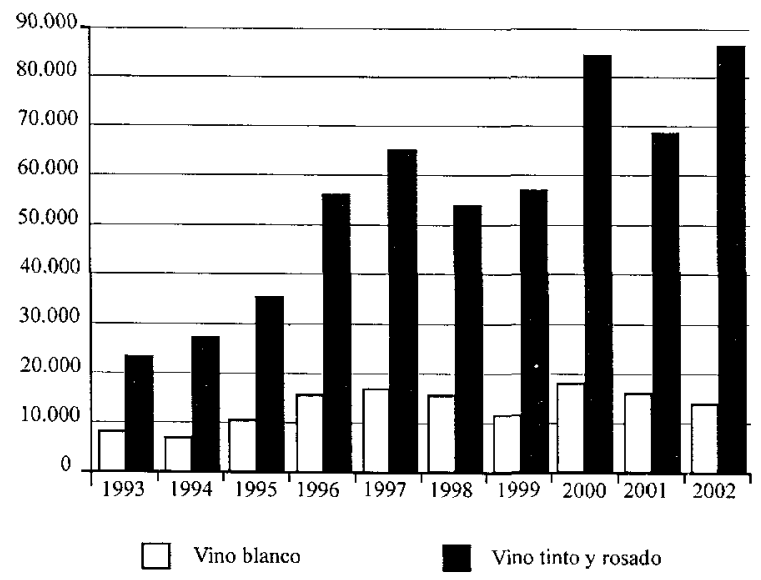

Figura 2. Las producciones del viñedo de Somontano. 
La problemática abordada en este estudio se reparte en tres niveles: en el desarrollo del viñedo del Somontano, ¿cuál sería el peso del condicionamiento natural, en sentido lato, frente a las opciones económicas?; en el juego entre diferentes actores -productores, comerciales, administrativos-, ¿quién se adelantará a los demás?; finalmente, ¿cómo se va integrando la denominación Somontano entre las producciones vitivinícolas aragonesas, españolas e incluso europeas, y en qué hueco de comercialización se coloca?

\section{Un viñedo nuevo en una vieja tierra de vino}

\subsection{Una nueva Denominación de Origen da nuevo color al nombre de una comarca}

Pedida en 1974, creada el 30 de octubre 1984, modificada en 1992 y 1994, la Denominación de Origen Somontano viene a revitalizar el nombre de una antigua tierra de la cuenca del Ebro. Somontano, en el habla aragonesa, significa "pie de monte". Dicho espacio abarca el pie de monte comprendido entre las sierras exteriores del Pirineo al norte - de Guara $(2.077 \mathrm{~m})$, de Loarre y de la Peña- y la llanura del Ebro al sur. Existe, simétrico al oscense, un Somontano ibérico en la orilla derecha de la cuenca del Ebro.

El Somontano pirenaico está compuesto por un conjunto de "hoyas" entre las que destacan, de oeste a este, las de Ayerbe, Huesca y Barbastro. Dichas cuencas de erosión están rellenas de materiales arrancados a las sierras circundantes durante el terciario, amontanados y labrados de nuevo por los sistemas erosivos posteriores. La Denominación de Origen Somontano concierne únicamente a las cuencas regadas por los ríos Alcanadre, Vero y Cinca; incluye en sus márgenes algunas zonas de la Ribagorza al este, y de los Monegros al sur. La zona de producción concierne a 43 municipios. Dé las 205.000 ha del conjunto, 95.000 están cultivadas pero sólo 2.700 ha de viñedos pueden utilizar hoy día la Denominación de Origen Somontano. Se concentran en su mayor parte alrededor de Basbastro, beneficiándose de la Denominación 445 viticultores.

\subsection{Un viñedo dirigido por un Consejo Regulador}

La gestión de la Denominación por un Consejo Regulador permitió crear, desarrollar y proteger una nueva producción que se superpuso y fue arrinconando a la antigua. El Consejo Regulador viene a ser un organismo administrativo que depende del Departamento de Agricultura del Gobierno de la Comunidad Autonóma de 


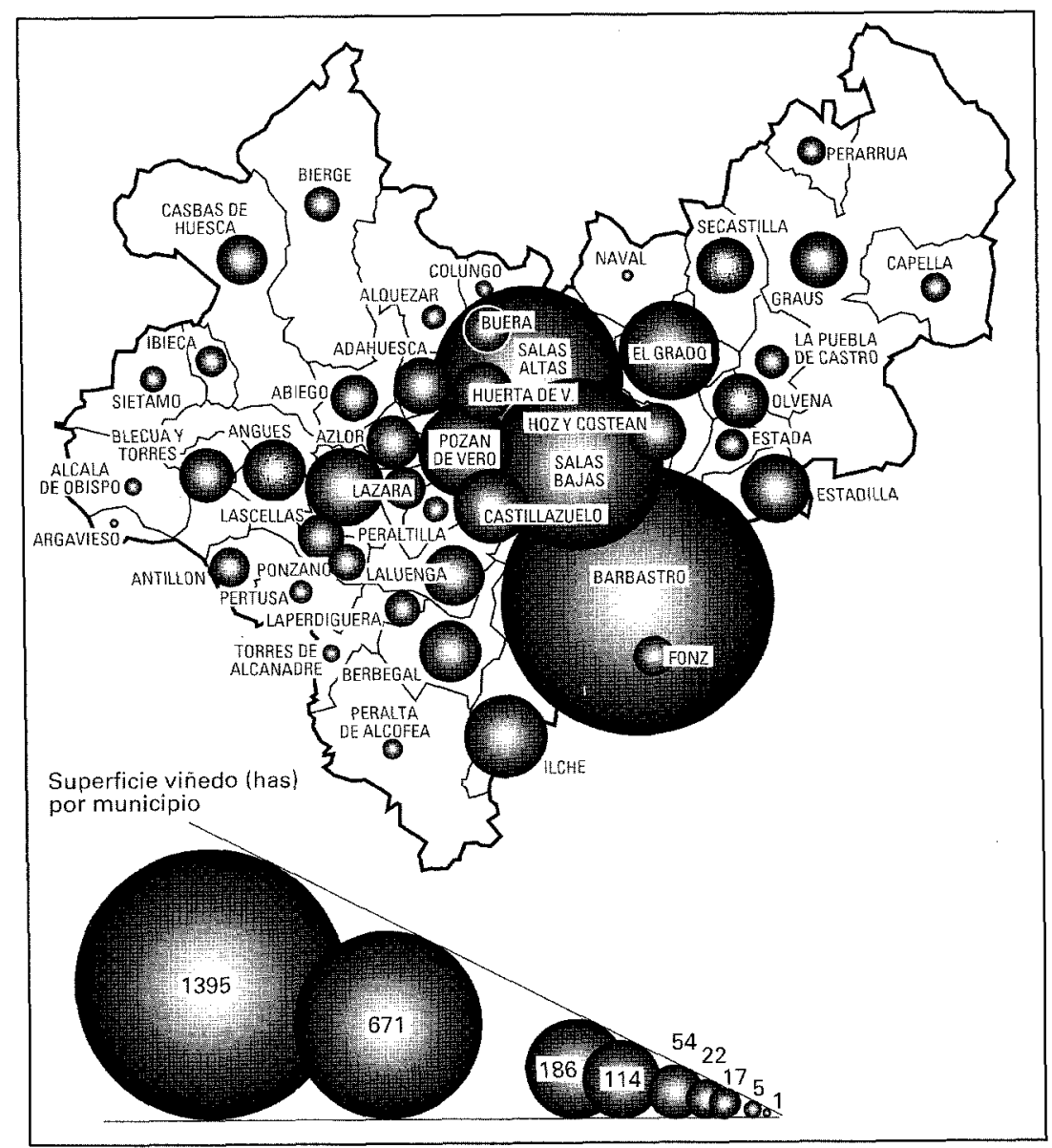

Figura 3. El viñedo de Somontano, superficie por municipio.

Aragón. Es su cometido orientar, ayudar, vigilar y controlar la producción, elaboración y calidad de los vinos que gozan de la Denominación de Origen Somontano.

Su acción se va ejerciendo a lo largo de la cadena vitivinícola, desde la selección de parcelas y cepas, luego la elaboración de los vinos, hasta su llegada al mercado y, si es el caso, su exportación.

El Consejo Regulador se compone de 14 miembros. Lo dirige el presidente, nombrado por el consejero de Agricultura. Los viticultores y las bodegas tienen, respectivamente, 5 miembros, el consejero 2 . Un secretario nombrado por el mismo Consejo carga con la dirección de la administración, que consta de media 
docena de funcionarios. La oficinas están instaladas en Barbastro, en los locales del antiguo Hospital, recién restaurado, que cobija además un Museo del Vino y un restaurante gastronómico. Esta estructura técnico-administrativa funciona según el mismo modelo que los otros tres viñedos aragoneses con denominación de origen que son Cariñena, Calatayud y Campo de Borja. Tiene un logo, se dedica a promoncionar el viñedo y se confirma como la fuente de toda la viticultura del Somontano.

\subsection{Se trata de una vieja tierra de vinos}

El cultivo de la vid se remonta al siglo $\mathrm{V}$ antes de nuestra era, con un desarrollo notable debido a la romanización.

Después del período de dominación musulmana, el viñedo se fue reponiendo gracias a los monasterios, pero es en el siglo XIX cuando el viñedo conoce un amplio desarrollo, merced a la crisis de la filoxera que arruinó el viñedo francés, provocando el auge de la producción española en su conjunto, incluída la del Somontano.

En esta época de bonanza de la producción vitivinícola hay que recalcar el papel que representó la familia Lalanne, de origen bordelés. Las exportaciones hacia Francia estaban favorecidas, además, por un acuerdo comercial firmado por ambos países en 1877. El viñedo duplica entonces su superficie, pasando de 29.023 ha en 1860 a 54.026 en 1890 (Sabio-Alcuten, A., 2001).

Sin embargo, no duró mucho semejante auge. Al reanudarse la producción francesa, mediante el recurso a cepas americanas, y llegar la filoxera en Aragón, y al caducar en 1891 los acuerdos comerciales con Francia, bajo el ministerio Meline, se produjo en el último decenio del siglo XIX la ruina de los viñedos aragoneses. Su recuperación no fue sino parcial. Así, en el partido de Barbastro, que corresponde en su casi totalidad a la denominación actual, la superficie del viñedo bajó de 13.908 ha en 1889 a 4.285 en 1922, aun cuando las estadísticas no son del todo fiables. La superficie de viñas fue marcando dientes de sierra, variando de 2.000 a 4.000 ha.

La producción no rebasąba el marco local. El vino se elaboraba de modo artesanal en bodegas privadas, se vendía a comerciantes catalanes o navarros que lo usaban para cortes, o a las empresas de vino locales que se mostraban bastantes tímidas, con excepción de Lalanne.

En ese contexto de astenia vitivinícola es donde se inscribe, en 1964, la creación de la Bodega Cooperativa, que salvó al viñedo somontanés de un ocaso fatal. 


\subsection{El entramado de las condiciones naturales}

Las tierras sirven tanto de soporte para el cultivo de la vid como de referencia paisajística y cultural para promoción y venta de los vinos.

El Somontano es un pie de monte con un declive de norte a sur, cuya altitud baja de 650 a $350 \mathrm{~m}$. Dibuja el borde sur del sistema de las Sierras Exteriores del Pirineo. El sustrato geológico se compone de calizas del secundario, sedimentadas en el jurásico inferior: las facies muestran piedras ligeramente rubificadas, de tonos de un rosado viejo que se dan tanto en los espacios rurales como en los edificados. Esa tonalidad rosácea viene asociada a menudo con la producción vitícola, tanto en los folletos publicitarios y los edificios vitivinícolas como en las fotos. Ese color brinda una "imagen" al viñedo novel.

El Somontano es también cuenca de erosión. Los materiales arrancados al Pirineo y ahí depositados, se remontan al fin del secundario (aptiano) o del terciario. Luego, sucesivos sistemas erosivos los labraron y modelaron, dejando cada uno su huella como herencia. Estos episodios consecutivos se pueden leer en los paisajes naturales del Somontano: ahí es donde se inscribe el viñedo. En último término, la sierra con acantilados de caliza dorada que domina hileras de colinas alargadas, o lomas. A veces en el paisaje descuella un cerro, testigo de una antigua superficie de erosión. Es en uno de éstos donde se yergue el monasterio de El Pueyo de Barbastro, cuya silueta firma el horizonte de los paisajes vitícolas del Somontano. Ese peñasco fue usado en las etiquetas de las botellas, en los albores de la Bodega Cooperativa. Ahora vuelve a asomar en los folletos de la Bodega Enate.

Los espacios naturales incluyen también extensiones de suave declive, jirones de antiguos glacis. Unos profundos barrancos recortan las partes llanas, a veces en pequeñas unidades, las más en trozos de mayores dimensiones. El conjunto muestra unos paisajes llanos, en contraste con el horizonte montañoso, quebrados brutalmente, en los que resaltan los cultivos. Éstos se concentran en los llanos, mientras que las pendientes se abandonan a la vegetación arbustiva. La vid arraiga en estos paisajes mediterráneos de postal; también aparecen los trigales y sus barbechos, las huertas a lo largo del río Vero, los almendros y olivos de hojas de azul-verde y, sobre todo en la periferia de Barbastro, los nuevos viñedos. El conjunto está sumido en esa luz de la España continental que recalca las calizas rosadas y los suelos, de un pardo rojizo.

Los paisajes naturales de los cañones de la sierra de Guara, muy próxima, atraen a los turistas, cada año más numerosos. Éstos pueden descubrir el vino de Somontano al venir a visitar el viñedo, que se convierte un "identificador" cultural de la región. Los suelos son poco feraces, pero básicos y que drenan bien, rasgos muy favorables para el crecimiento de la vid.

Las condiciones climáticas colocan al Somontano en el límite de mundo ecológico de la vid. 
La temperatura media anual es de $11^{\circ} \mathrm{C}$; los veranos son calurosos, tórridos de julio a agosto, y los inviernos fríos, con fenómenos de inversión térmica en las hoyas de Huesca y Barbastro. Éstas aparecen cubiertas de niebla, a veces con escarcha, mientras que a partir de los $900 \mathrm{~m}$. de altitud las sierras están despejadas y a pleno sol, si bien hace frío. Las olas de frío se abaten con una violencia asoladora; en primavera pueden helar la vid, en mayo e incluso hasta en junio.

El régimen de precipitaciones acentúa el de las temperaturas, bajando aquellas de norte a sur y de oeste a este. La media anual oscila en torno a $500 \mathrm{~mm}$, con un déficit notable en julio y agosto, lo que exige el riego de los nuevos pimpollos. Pero las fuertes lluvias de otoño y primavera rellenan los acuíferos y hacen desbordarse a los arroyos. Llegan bajo forma de chubascos no muy prolongados, de sorprendente intensidad, que pueden caer hasta finales de junio. Pasado el 15 de agosto, las tormentas estallan sobre el Somontano y su frecuencia aumenta en septiembre, preparando la vuelta de las lluvias otoñales. Es en esta fecha cuando empieza la vendimia. La sequía véraniega constituye una desventaja para los brotes nuevos, pero permite a los racimos almacenar altas tasas de azúcar. Estas duras condiciones exponen al viñedo del Somontano a la amenaza permanente de olas de frío primaveral y del déficit hídrico en el estío, pero permiten el crecimiento de un viñedo rústico. Al trasladar las condiciones climáticas a las cualidades del vino, la publicidad se vale de estos rasgos como argumentos de venta que se traducen en carácter, poder, fuerza...

Las cepas autorizadas en la Denominación de Origen son cada vez más numerosas.

En 1984, cuando se otorgó la Denominación, tan sólo se admitieron las cepas tradicionales del Somontano. Para los tintos se trataba de la Moristel; se supone que la Moristel es oriunda de Aragón, era la cepa base para la producción de tintos tradicionales. A esa cepa se añadía la Tempranillo, procedente de la Rioja, la Garnacha, tinto muy difundido por toda España, y la Parraleta, usads para vinos de solera.

Para los blancos, la cepa del Somontano es la Macabeo, que llega a la madurez con característicos racimos gruesos, con alta densidad de azúcar; la Macabeo proporciona vinos muy olorosos. Además de esta cepa indígena se autorizaron la Alcañón y la Garnacha Blanca, variedades muy usadas en España.

El reglamento de la Denominación se revisó en dos ocasiones, 1992 y 1997, para permitir nuevas cepas. En 1992 se admitió para los tintos la cepa bordelesa CabernetSauvignon. Es muy grato poner de relieve que esta cepa la introdujo la familia Lalanne en su finca de San Marcos, un modo de adelantarse a todos con la respetabilidad que proporciona la tradición. Más que otra cosa fue une decisión de enológo, lanzada en su tiempo por el de la Bodega Cooperativa, destinada a producir vinos más conformes con los que demanda el mercado. El mismo proceso se siguió para los blancos, con la ayuda de la Chardonnay, cultivada para una producción mono- 
varietal que brinda una nueva imagen al Somontano. Ese refuerzo fue usado por las nuevas bodegas.

El mismo proceso de ruptura con las cepas tradicionales y de apertura a las extranjeras, muy usadas por todo el mundo vitivinícola, siguió en 1997. Entonces se aceptaron para los tintos las cepas Pinot Noir, muy usada en Champagne, Borgoña y Merlot, oriundas del Medoc. Para blancos, la Gewürtztraminer alsaciana, totalmente alóctna, tanto en Somontano como en España, recibió permiso de entrada. Así, en un plazo de 13 años, el viñedo del Somontano pasó de un acervo de cepas autóctonas a un espectro cosmopolita que se encuentra por todos los viñedos de exportación de Europa, pero también en California, Autralia, Chile, África del Sur y México. Ese universalismo, que concierne sobre todo a la Cabernet-Sauvignon, se ciñe a la lógica de viñedos de enólogos más afines a las cepas que a los terruños, lógica que de aquí en adelante impregna al Somontano.

\section{El Somontano: una creación técnico-financiera}

\subsection{Unos paisajes nuevos en el campo del Somontano}

Las nuevas viñas contituyen paisajes construidos según un modelo técnico: hileras trazadas con laser, postes de hierro galvanizado para evitar el arroyado, cuando desde siempre las vides se arrastraban por el suelo. Las nuevas viñas se riegan por goteo mediante un tubo de plástico que discurre a lo largo de las hileras, alimentado por tuberías subterráneas. Esos paisajes agrícolas ordenados, geométricos, desherbados químicamente, se encuentran sobre todo al norte de Barbastro, en el municipio de Salas Bajas, en el valle del Vero, y, más al oeste, en Adahuesca y Abiego. En otras partes, la presencia de viñas nuevas es mucho menor.

Las dinámicas del espacio y del paisaje en la campiña del Somontano están trastocadas por la creación del nuevo viñedo.

Enate, pueblo situado al este del término municipal de Barbastro, en el valle del Cinca, viene a ser el ejemplo emblemático de semejantes mutaciones. Comprado por la sociedad vitivinícola Viñedos y Crianzas del Alto Aragón, que precisamente eligió como marca comercial el nombre del pueblo, lo mejor de sus tierras están cubiertas hoy de viñas. La antigua ocupación rural de Enate -trigo, almedros y olivos mezclados- desapareció, según se puede ver en un amplio fresco que decora la fábrica vinatera de la Bodega Enate, pero ésta se halla en Salas Bajas, a unos quince kilómetros del pueblo epónimo, cerca de las demás bodegas (Enate: una bodega de nuestro tiempo, 2001). 
El paisaje de las nuevas viñas ha acabado con el del viñedo añejo. Antaño se cultivaba sin rodrigado, corriendo los pámpanos por el suelo, sea en bloque, sea a tornallo, es decir un fila de cepas cada 5-10 m, a veces en torno a un campo sembrado de trigo, avena, a veces con almendros $\mathrm{y} / \mathrm{u}$ olivos. Si bien los almendros conocieron un renovado éxito a poco de ingresar España en la Unión Europea, hoy pierden terreno ante la nueva viña. Durante el invierno 2000-2001, se arrancaron entre Abiego y Adahuesca extensas parcelas de almendros en las que se plantaron cepas inmediatamente.

En la tierra del Somontano la vid es el elemento dinámico frente a los cultivos tradicionales: la cerealicultura y la arboricultura de olivos y almendros, que se han estancado o progresan poco. Es la base de la nueva especulación, después de la ganadería en granjas de fuerte rastro oloroso, creadas en los setenta.

Así, el campo somontanés se va simplificando en sus componentes, presentando unos ager que disminuyen el cultivo especulativo de la vid, cerealicultura en amplias parcelas labradas "año y vez" y, por otra parte, unos saltus que progresan con esos procesos de abandono del monte que favorecen su ensanchamiento. Esta dicotomía caracteriza actualmente los paisajes rurales del alto Aragón, en los cuales sólo el viñedo va catalizando su dinámica. Esta evolución se observa fácilmente de un año al otro por quien cruza con regularidad los términos municipales de Barbastro, Salas Altas, Salas Bajas y todos los municipios de una y otra parte del río Vero.

Las bodegas, cuyas estructuras se analizarán más adelante, van modelando también el paisaje rural, de modo diferente según su edad y su tamaño. La mayoría se concentran en un sector muy preciso al norte de Barbastro. Las más antiguas, como Lalanne en su finca de San Marcos, están sumidas en las frondas de su parque de plátanos tutelares; lo mismo pasa en Fábregas. La bodega Monclús en Radiquero, pequeña aldea de Alquézar, es un edificio de tipo hotelito que alberga un cotizado restaurante. Las tres mayores -Pirineos, Viñas del Vero y Enate- imponen su marchamo en el paisaje, con la importancia y el estilo de sus edificios.

En todos los casos lo edificado corresponde a la política comercial definida por las empresas. Aquí, la arquitectura agroindustrial prolonga la campiña que la abastece con su materia prima: las uvas. Como el producto final es un alimento, se pone de relieve la trabazón con la tierra madre, ya que la referencia a un terruño identificado autentifica la buena calidad del producto. Así, el edificio vitivinícola actúa como mediador entre el componente básico, que surge del binomio planta-suelo, y el producto vendido al final de un largo proceso técnico-comercial, muy alejado del terruño. Más adelante se abordarán los dispositivos arquitectónicos de las bodegas que mediatizan las andaduras comerciales de cada empresa.

Sin embargo, son factores invisibles los que condicionaron la creación de esos nuevos paisajes. El ingreso de España en la Unión Europea en 1986 fue uno de los 
pilares de la creación del actual viñedo. La adhesión a Europa permitió conseguir ayudas comunitarias. En España, el decreto 808 de 1987 formaliza los programas de ayudas para mejorar las estructuras agrarias gracias a los fondos europeos. La nueva Denominación de Origen las viene aprovechando desde el principio. En 1988-1989 el viñedo "despegó" literalmente con 204 y 369 ha de nuevas viñas plantadas, respectivamente. En 1999, casi el $80 \%$ de las plantaciones no había cumplido 10 años: el Somontano es un viñedo nuevo.

La Constitución de 1978 permitió transferir a las comunidades autónomas numerosas competencias que antes eran del Gobierno central, lo que Aragón aprovechó para acelerar su politica de regionalización. Así fue como, en 1992, el Gobierno aragonés intervino para evitar la quiebra de la Bodega Cooperativa de Barbastro a causa de intervenciones muy voluntaristas. El Somonano es un viñedo aragonés desde un punto de vista espacial, pero, por cierto, también desde un punto de vista político. Fueron decisiones políticas y administrativas las que permitieron edificar una estructura vitícola que sirve de zócalo a la actual actividad vinícola.

\subsection{Las bodegas integran la producción}

El actual dispositivo de vinificación y, sobre todo, de comercialización funciona merced a todo un sistema de empresas llamadas bodegas. La palabra bodega significa cueva para elaborar y conservar el vino y despide un olor a terruño; puede también traducirse por jaraíz, cuando se trata de la reserva de vino de la casa. Pero también designa una tasca o bar donde se despacha principalmente vino, pero también tapas y bocadillos. En una palabra: todos los ingredientes reunidos en un lugar de convivencia y de intercambio, elementos de la sociabilidad ibérica. Actualmente, la palabra bodega designa a un lagar industrial en el cual se vinifican los mostos y se hace la crianza de los caldos que, luego, se venden en parte allí mismo.

Cualquiera que fuese el significado, la palabra viene del griego apotheke, que designa un depósito, un almacén, una tienda, y constituye ejemplo clarísimo de doblete, ya que etimológicamente la palabra se convierte en botica, farmacia en español antiguo, y en bodega, ésta, al principio, entendida como lugar de negocio y, luego, especializado en vino.

Las bodegas que han tenido un gran desarrollo son fábricas de vino con un local para la venta directa. Pero la connotación muy industrial del vocablo factoría desdice bastante de las líneas de acción comercial de dichas empresas. En el Somontano, las bodegas son empresas que tienen derecho a vender vinos de la Denominación. Las más importantes poseen un viñedo, compran uvas a los viticultores, vinifican y se dedican a la comercialización. Se trata de las Bodegas Pirineos, Viñas del Vero y 
Enate. Les siguen estructuras más pequeñas como Bodegas Lalanne, Blecua o Fábregas. En el último escalón, las más pequeñas no hacen más que embotellar y vender vinos vendimiados y vinificados por vitivinicultores cuyas uvas corresponden, evidentemente, a las especificaciones del Consejo Regulador. Estos mismos establecimientos pueden llevar a cabo la crianza de vinos comprados jóvenes. De hecho, las pequeñas bodegas mantienen los lazos con los tradicionales "vinos de la casa", inclusive aunque la índole de los productos ha cambiado sustancialmente y los actuales circuitos de comercialización están fomentados por la nueva Denominación. Se trata de las Bodegas Monclús, Borruel, Valdovinos y Dalcamp, estas tres instaladas cerca de Huesca.

Grandes y pequeñas bodegas no pertenecen al mismo mundo financiero, técnico o comercial. Pero todas integran las produciones merced a la comercialización.

Grandes o pequeñas, las bodegas actuales son las herederas del negocio del vino en el Somontano (Consejo Regulador, 2001).

La Bodega Lalanne se remonta al siglo XIX, creada por esa familia de origen bordelés. Se valió de la llegada del ferrocaril a Barbastro en 1880 (Wais, 1974) para desarrollar la producción de vinos y exportarlos a la vez hacia Francia y Argentina. En el contexto de la recesión posfiloxérica de la primera mitad del siglo XX, la casa Lalanne se salvó apoyando su producción en la finca de San Marcos, al norte de Barbastro, y desarrollando una política de marca con producciones de tintos y blancos champanizados.

La Bodega Pirineos es la heredera de la Bodega Cooperativa creada en 1964. El Somontano perdía su población, sufriendo un importante éxodo rural. Tras la emigración hacia Francia por razones económicas, pero también a resultas de la guerra civil y sus consecuencias, se produjeron grandes desplazamientos hacia Cataluña, Zaragoza y Monzón, donde las industrias estaban en pleno auge. El campo del Somotano iba desangrándose, con el consiguiente abandono de sus cultivos; en primer lugar de la vid, ya que era el que requería más trabajo. Es en este contexto de declive de la agricultura cuando se abrió, en 1964, la Bodega Cooperativa de Barbastro, cuyos edificios se asentaron en la carretera de Naval, cerca de la encrucijada con la de Alquézar, frente a las Bodegas Lalanne y su finca San Marcos, en esa " $y$ " carretera que habría de convertirse en el centro de gravedad del actual viñedo.

Esta iniciativa no nació de la nada; fue la reacción después de una larga recesión. Se preparó con una concienciación de los viticultores, encauzada por los consejeros agrícolas locales, que dependían entonces del Ministerio de Agricultura, mediante conferencias, demostraciones de tracción mecánica y cursillos de enología. En el juego de diferentes actores hay que destacar la personalidad de un notable rural, el Dr. D. Antonio Aznar, que fue durante 17 años director de la Cooperativa. Ésta se puso en 


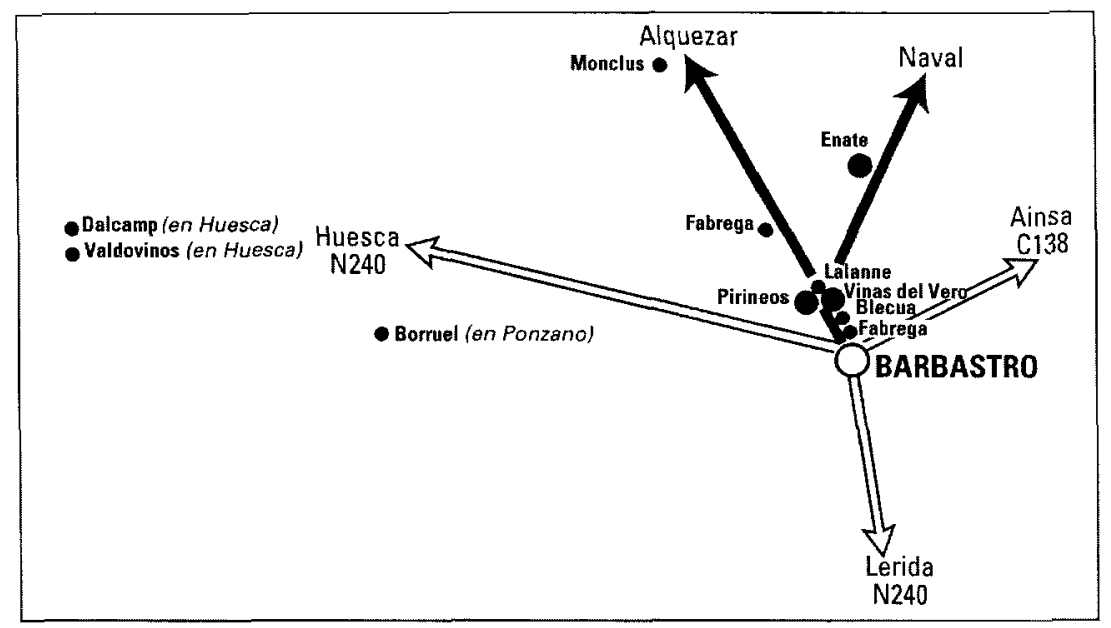

Figura 4. La "Y» de las bodegas del Somontano.

marcha en 1964 con 192 socios, valiéndose de la legislación de 1942 sobre movimiento cooperativo. Los objetivos pregonados eran desarrollar una industria agroalimentaria, prescindir de intermediarios y asegurar a los campesinos un buen precio de sus uvas.

El primitivo proyecto contemplaba incluso la creación de un banco cooperativo que jamás vería la luz. La primera vendimia se vinificó en 1965 y, al año siguiente, la Cooperativa contaba ya con 300 socios, consiguiendo ralentizar el declive de la viticultura e inaugurando una activa política de comercialización del vino embotellado. Las etiquetas usadas venían con el lema Somontano de Sobrarbe y las marcas escenificaban los paisajes comarcales: Montesierra, Camporrocal, pero, sobre todo, el monasterio del Pueyo de Barbastro, la marca Monasterio. Éste, encaramado en una peña, desempeña ese papel de geosímbolo que da carta de hidalguía al actual viñedo, como la dio al de los años 60 Sabio-Alcuten, 2001).

A la vez, la Bodega Cooperativa intentó conseguir el reconocimiento legal de la Denominación. Ya en 1968 se inician trámites para conseguirla, pero sin éxito. Los poderes públicos son muy remisos a otorgarla y, si lo hacen, es parsimoniosamente (Milans del Bosch, 1995). Esto no es óbice para que, al mismo tiempo, los vinos de Cariñena, en la provincia de Zaragoza, posean la Denominación desde el 25 de mayo de 1960 y se alcen como adalides de dicha referencia vitivinícola aragonesa.

Estos primeros trámites prepararon las mentes y facilitaron más adelante el rápido surgir de la Denominación. El reconocimiento de ésta en 1984 y la transformación del viñedo trastocaron la estructura vitivinícola local. La Bodega Cooperativa trató de 
adaptarse a ella, invirtiendo cuantiosamente al final de los años 80 en ultramodernas instalaciones de vinificación. Para llevar a cabo esta empresa de renovación, recibió ayudas públicas, pero tuvo que recurrir al empréstito. Esa arriesgada déuda no acarreó un cambio de mentalidades y, para los socios, la Cooperativa siguió siendo solo el sitio donde se entregaban las uvas. Los negocios tomaron mal cariz; enseguida le resultó imposible a la Cooperativa pagar los créditos contraidos, e incluso pagar las uvas a los socios. Es la quiebra, en 1992.

La salvación la brindó el Gobierno autonómico, entonces dirigido por una coalición Partido Aragonés Regionalista/ Partido Popular desde 1991. El Gobierno fomentó la creación de una nueva sociedad anónima que se apellidó Bodegas Pirineos. En cuanto al capital que las controla, la Caja Rural posee el $30 \%$ de las acciones, el Instituto Aragonés de Fomento (IAF), que emana del Gobierno regional, el 20\%, las bodegas privadas Enate y Viñas del Vero el 25\%. Los antiguos socios no eran ya sino accionistas minoritarios, con el $5 \%$ del capital. La nueva sociedad llevó a cabo une profunda restructuración, acatando las normas de gestión capitalista y los gustos del consumidor. La Cooperativa del Somontano de Sobrarbe hizo mutis, pero, pese a todo, sirvió de enlace entre la herencia postfiloxérica de los años 50 y el nuevo viñedo que sigue desarrollándose hasta hoy día.

Las bodegas Viñas del Vero y Enate fueron se crearon en 1986 y 1991, respectivamente. La primera se montó con varios aportes de capital: el Gobierno autonómico con el $38 \%$ de las acciones, las cajas de ahorro Ibercaja y de la Inmaculada con el $12 \%$ y $25 \%$, y la Sociedad Minera Catalano-Aragonesa (SAMCA), que pertenece a D. Ángel Luengo, con el $25 \%$ restante. Este accionista posee, por otra parte, intereses en la industria química de Monzón. El negocio queda, pues, en manos aragonesas. Viñas del Vero se instaló en una parte de la finca Lalanne, de la cual recuperó dos lagares que sirven para crianza de caldos, mientra que realiza la vinificación en instalaciones muy modernas.

La Bodega Enate es la recién nacida, al menos por el momento. Posee viñas en torno al pueblo epónimo ya citado, pero por razones comerciales asentó su bodega en Salas Altas. Sus edificios señorean el pueblo y son ejemplo de una "arquitectura enológica", funcionalista y muy original, que consta en el marchamo de la empresa. Enate pertenece a la sociedad anónima Viñedos y Crianzas del Alto Aragón. El accionista único es un capitalista madrileño, Luis Nozaleda, cuyos intereses se reparten entre industria y obras públicas. La misma sociedad participó, a petición del Gobierno aragonés en la creación de Bodegas Pirineos. Acaba de realizar una cuantiosa inversión en el control y modernización del establicimiento termal de Panticosa, en el Valle de Tena, en el curso superior del Gállego, al pie del Balaitus, en la alta montaña.

Las restantes bodegas, más modestas, crían y embotellan vinos comprados. Pero es regla general que la galaxia de bodegas ponga un límite por abajo a la comercialización, ya que son solo ellas las que disponen de la Denominación. Según los esta- 
tutos, cada viticultor puede comercializar si acata los criterios fijados por el Consejo Regulador; de hecho, tan sólo las bodegas alcanzan ese privilegio. Por cierto, las pequeñas bodegas están muy próximas a los viticultores que les suministran las uvas, pero son las grandes, con su dinamismo comercial y publicitario, las que despachan la mayor parte de la producción. Las participaciones cruzadas ya mencionadas y el control de Blecua por Viñas del Vero no hacen sino reforzar la hegemonía de esas empresas capitalistas en el negocio de los vinos del Somontano.

Las "casas de pueblo" siguen produciendo vinos tradicionales con cepas y, sobre todo, con añejos de vinificación. Estos "vinos de la casa", así llamados por oposición a los de Denominación Somontano, representan al vino tradicional: de fuerte grado alcohólico, ásperos en la lengua, olorosos sin que sea preciso encontrar en ellos esas fragancias a frutas rojas o a plátanos, sobre las que hacen gorgoritos la revistas de enología.

Estos vinos difieren según las casas, también con los años e incluso con las barricas: no pueden salvar la doble valla de la comercialización y de la calidad constante y uniforme que exige la flamante Denominación. Se pueden citar entre estos "vinos de la casa" a los de Casa Mateos en Salas Altas, Casa Salas en Radiquero, Casas Moreu y Fumanal en Alquézar, de las casas de Bespén, que pueden llegar a 19. Pero las más de las veces los producen, en escasa cantidad, campesinos ya mayores, lo que anuncia su ocaso y desaparición; se pliegan a la lógica de la nueva situación. Son unos neandertales vitícolas. La Casa Mateos de Salas Altas, sin embargo, se sale con la suya aprovechando a la vez un renombre local logrado ya mucho antes de la creación de la Denominación y del auge de la demanda provocado por el debut del nuevo viñedo. Con 25 ha de cepas añejas, el dueño produce vinos de modo artesanal, a veces adaptando las nuevas técnicas a sus medios: así, por ejemplo, usa tanques de refrigeración lechera para enfriar los mostos y limitar el grado de sus vinos. Hoy día vende toda su producción, la mayor parte en garrafas y solo en una ínfima proporción en botellas.

\subsection{Las técnicas de vendimia y vinificación: la "enologización"}

Las técnicas de vinificación seguidas en el Somontano son las mismas que se han impuesto en todos los grandes viñedos del mundo. En el entorno que forman las grandes bodegas, las cubas de fermentación de acero inoxidable, las instalaciones de refrigeración, las naves de descarga de la vendimia y las enormes prensas configuran unas factorías llenas de tubos que no dejan de recordar a los de la industria química. Estas técnicas de vinificación muy modernas vienen inscritas en los pliegos de condiciones de la Denominación y su aplicación está debidamente controlada por el Consejo Regulador. El grado alcohólico ( $14^{\circ}$ como máximo para los tintos) la acidez mínima, la tasa de anhídrido sulfúrico, las cualidades organolépticas sobre colores, el aroma o el sabor están detalladas con perfecta precisión. 
Se fijó un tope a los rendimientos y, en agosto, los racimos sobrantes se cortan y se abandonan en el suelo, donde se secan. El objetivo es llegar a 0,75 litros de vino por kilo de uva; no se trata de conseguir que "mee la viña". El control de calidad corre parejo con el de cantidades. Las uvas, recogidas a mano, están tratadas químicamente. En las grandes bodegas, la elaboración de los mostos se controla mediante ordenadores desde su llegada a la cuba hasta su fermentación. Pasa lo mismo con el control de los malo-lácticos, la puesta en barricas y la gestión del stock de botellas. La vuelta a la tradición, escenificada como en un teatro durante la visita de las instalaciones, se practica en Enate con el "bâtonnage" de blancos. Las grandes bodegas del Somontano se parecen a las de todos los viñedos modernos: el enólogo ha sustituido al maestro de lagar y la mayor parte se han formado en Burdeos. Si "la Facultad de Enología de Burdeos provoca envidia" (Le Monde, 23/01/2002) debería cuidar de salvaguardar "la mano izquierda" tan ampliamente usada en otros lugares.

El pliego de condiciones del Consejo Regulador apunta que la crianza debe hacerse en la zona de producción. Se debe criar el vino dos años por lo menos, y durante más tiempo según se trate de crianza ( 2 años, de ellos 6 meses en barrica de roble), reserva ( 3 años para los tintos, 2 para los blancos, con paso obligado por barrica), o gran reserva ( 2 años en barrica y 3 en botella para los tintos, y 4 años, de los cuales 6 meses en barrica, para los blancos).

No se puede dejar de apreciar que toda la publicidad montada en torno a estas operaciones insiste constantemente en la mezcla de tradición y modernidad.

En cuanto a tradición, las más de las veces se trata de un argumento para vender y, si no, consiste en disponer algunas cubetas, prensas y barricas antiguas a la puerta del jaraíz, de las tiendas de venta directa o en los catálogos de promoción. La modernidad es una exigencia para producir los vinos deseados. La Cooperativa fue a la bancarrota por invertir demasiado en costosas instalaciones de vinificación. Pero esta carrera a la modernidad no excluye algunos quehaceres manuales como el "bâtonnage" que, sin embargo, no era usual en la tradición del Somontano. En último término, lo importante es vender la producción, al precio más alto posible.

\section{Vender: la etiqueta "Somontano" en la "bodega mundial"}

El joven viñedo del Somontano debió su pujante desarrollo a unos eficaces recursos comerciales que consistían no sólo en vender un vino gracias a sus calidades genuinas, sino tambien valiéndose de todo un entorno geográfico y cultural. 


\subsection{Opciones de marketing muy punteras}

La promoción del viñedo la desarrolló, primero, el Consejo Regulador. La sede social ocupa los edificios renovados del antiguo Hospital, próximo a la plaza de toros, en la periferia del casco urbano de Barbastro.

Una señalización omnipresente encamina al visitante hacia las bodegas o la sede del Consejo Regulador. Estos rótulos trazan así el esbozo de una ruta del vino somontanés que, sin falta, acaba en una de las bodegas que se pueden visitar, donde también se pueden probar vinos y, sobre todo, comprarlos directamente. La viña toma así posesión de los paisajes carreteros del Somontano central, corazón del viñedo, y se convierten en un elemento más del aparato comercial.

El Consejo Regulador es el editor de una importante obra titulada "Vinos de siglo en el Somontano de Barbastro" (Sabio-Alcutén, 2001) que cuenta la epopeya de la viña desde su creación. El título, muy evocador, de este libro de lujo -cuatricromía, papel cuché, iconografía abundantísima- sugiere que la tradición vitivinícola se mantiene desde sus orígenes. Se soslaya el gran quiebro que representó la nueva Denominación, y el paso a la nueva viticultura se rebaja al nivel de las mutaciones imprescindibles, mero tributo que hay que pagar al progreso en marcha, que se resume en la leyenda de una de las numerosas fotos (Sabio-Alcutén, 2001, p. 100) que muestra un lagar de crianza de champán: "Vinos nostálgicos y vinos científicos".

Los rigurosos artículos históricos a los que nos referimos, se consiguieron después de investigar en los archivos. Esas aproximaciones científicas, en cambio, van preparando el escamoteo del actual período, tratado en un texto periodístico atiborrado de superlativos y que presenta al Somontano como el mejor de los mundos vitivinícolas. Al fín y al cabo, el organismo de arbitraje se involucra a sí mismo, con el riesgo, a corto plazo, de perder la necesaria distancia para salvaguardar el proyecto inicial.

\subsubsection{Las pequeñas bodegas sacan sus propios triunfos}

La Bodega Lalanne, la de mayor abolengo, presenta los viejos edificios del Castillo San Marcos, según la más castiza tradición bordelesa de construcciones del siglo XIX, con viejas prensas fuera de uso y lagares de crianza de seculares bóvedas. Aquí no se saca a relucir la tradición; es parte integrante de la casona. Los folletos publicitarios alardean de esa dimensión bordelesa de la finca, cuyos fundadores eran negociantes oriundos de Barsac, cerca de Burdeos. Las botellas, de forma bordelesa, con su redecilla a la antigua, presentan etiquetas donde el nombre Lalanne, imagen de marca multiplicada, se repite en cada serie. Lalanne incluso cría un vino "champanizado", cava, con el nombre Lucrece Lalanne, pero que no puede preciarse del título Somontano. 
Las Bodegas Borruel, en Ponzano, ocupan casonas del siglo XVI. La Monclús, en Radiquero, es también un restaurante afamado, donde corren parejas la venta del vino y la convivencia, gracias a la acogida de la dueña. Este modesto establecimiento, que embotella vinos surtidos de la Denominación, evoca las añejas casas pueblerinas donde se producía vino "con todas las de la ley". El contraste es total con las propuestas de las tres grandes bodegas.

Para éstas, el mercado lo rige todo: es preciso vender la producción. Los enormes medios financieros, técnicos y comerciales proyectan tales empresas en otra esfera que la de las pequeñas casas.

Así es como Pirineos puede almacenar $71.000 \mathrm{~m}^{3}$, y llevar a cabo la crianza de 4.000 barricas. Sin embargo, cada una toca su particular partitura, lo que también se manifiesta tanto en la arquitectura de sus edificios como en los argumentos promocionales. ¡Heredera de la Cooperativa, pero ya empresa capitalista, Pirineos se ufana de guardar una relación provilegiada con sus socios, que le permite proveerse con uvas de primera!

Los edificios se apiñan en torno a la primera nave, con las cubas de fermentación de acero inoxidable, la maquinaria de embotellado y las cuevas de crianza. El salón de acogida para visitantes viene precedido por une serie de arquerías góticas con una plantación decorativa de coníferas. En las paredes de la bodega pueden leerse todas las etapas de su historia: Los vinos de Pirineos han recibido varios premios en concursos, lo que es una referencia para ventas; Pirineos emplea directamente a 52 personas, produciendo 4 millones de botellas en el 2000 y totalizó un volumen de negocios de 6,61 millones de euros (1.100 millones de pesetas); los viñedos de la casa y de los socios suman 800 ha.

Viñas del Vero se asienta frente a Pirineos, al lado de Lalanne, cuyos solares compró parcialmente, con dos lagares de críanza, y a unos centenares de metros de Blecua, que ha quedado bajo su control. Desde el punto de vista comercial, la casa prefiere tocar el registro de la tradición, por lo menos en lo que toca a los jaraices. Unas cubetas y prensas viejas están expuestas a la entrada, a modo de totems. En cambio, la fábrica de vinos es ultramoderna, igual que los métodos comerciales. Todas las botellas se comercializan bajo la marca epónima. Se distribuyen entre vinos añejos, vinos de cepas y sorprendentes "vinos de autor", de hecho, una creación del enólogo que antes trabajaba en la casa de enfrente, en Pirineos. El vaivén entre tradición y modernismo se repite en los folletos, que hacen hincapié en el refinamiento de la bodega y en las presentaciones, con el uso repetitivo de una estilográfica de lujo para trazar el nombre de la marca en cada una de las etiquetas.

Viñas del Vero se vanagloria de los premios recibidos, tanto en los concursos como por parte de revistas especializadas españolas y británicas. Se señala además 
que la compañía Lufthansa eligió productos de la marca para sus vuelos internacionales en primera clase. Ese detalle pone de relieve la imagen de producto de lujo al que se asimilan esos caldos y muestra el deseo de apertura y universalidad de Viñas del Vero, simbolizado por una compañía aérea de fama mundial. La sociedad emplea directamente a 125 personas, a principios de 2002 poseía en reserva 538.800 botellas y alcanzó una cifra de negocios de 122 millones de euros (2.000 millones de pesetas) en 2000. Las viñas que abastecen la bodega cubren 1.000 ha, de los cuales 650 son propiedad exclusiva de la sociedad.

Enate, la tercera de las grandes bodegas, rompe rotundamente con esa relación con el pasado. La más joven de esas bodegas hace patente la ruptura nada más instalarse, con un claro contraste entre el terruño vitícola y los edificios de la bodega, instalada en Salas Bajas. Esa voluntad de quiebro categórico se prolonga en la arquitectura, toda de ladrilllo y cristal, cuya mole domina el viejo caserío. Cobija las instalaciones de vinificación, la batería de cubas de fermentación, la larga nave donde envejecen en barrica los caldos y la de almacén de botellas. La construcción incluye también un salón de congresos y una sorprendente pinacoteca donde cuelgan los cuadros que han servido de modelo para sus etiquetas. Un folleto no vacila en afirmar: "Lejos de nosotros las tradícionales bodegas oscuras, polvorientas, húmedas, alumbradas con velas. Aquí queremos romper con esa tradición ridícula".

La misma obsesión de modernidad se concreta en las botellas, cuyas etiquetas reproducen cuadros de pintores tan famosos como Antonio Saura, José Beulas, José Manuel Broto, Enrique Torrijos, Victor Mira y Pepe Cerdá. A veces se añade un poema; así, Enate intenta aliar arte y vino. Este concepto se prolonga con actuaciones llevadas a cabo al alimón con el Museo Thyssen de Madrid, con la edición de la revista Enateca, y la celebración de coloquios y simposios en el anfiteatro. Al centrar su visión sobre lo esencial, la mente, con sendos apoyos en el terruño y la tierra pirenaica, Enate se afana para cautivar la franja intelectual y a la "gente guapa" de la nueva burguesía española.

Las produciones de tintos, blancos y rosados, que se reparten entre vinos jóvenes y vinos de crianza, se venden caros. El $60 \%$ de la producción se distribuye en España en restaurantes, tiendas de vino y en la cadena de grandes almacenes de alta calidad "El Corte Inglés". Las exportaciones se realizan a toda Europa, salvo Italia, sobre todo a Gran Bretaña, Países Bajos y Suiza; en América, a USA, México y Brasil, y en Asia, a Japón, Hong-Kong y Taïwan.

La bodega está muy concurrida, sobre todo en los meses de verano, con 10.000 visitantes al año que, las más de las veces, salen con sus compras. Hoy, la demanda es superior a la oferta. La bodega posee solo 370 ha en Enate y compra el 20\% de las uvas que vinifica a los viticultores de los pueblos vecinos. Enate emplea directamente a 65 personas. 
Actitud unánime: las bodegas mantienen une estrecha relación con el suelo y el terruño que nutre sus viñas. Su nombre -Pirineos, Vero, Enate- designa la sierra, un torrente rápido o un pueblo cuyo nombre es de raiz preindoeuropea, pero además usan también, implícitamente o no, toda la panoplia de paisajes del Somontano, con los secanos ante el telón de fondo montañoso, la vegetación, sus colores y sus geosímbolos.

\subsection{El Somontano frente a los viticultores vecinos: Un recién llegado en el mundo vitivinícola español}

En Aragón, la producción vinícola de denominación de origen la señorea la de Cariñena, que agrupa cerca de 15.000 ha, mientras que 1.183 se cultivan fuera ella. El Cariñena sigue simbolizando "lo aragonés" en la producción vitícola de la región. Los otros viñedos tienen menor extensión: 7.158 ha el Campo de Borja, 5.889 Calatayud. Los tres se sitúan al sur del Ebro, entre las montañas del Sistema Ibérico y el valle. Último vástago de los viñedos aragoneses, el Somontano ocupa un sitio aún más modesto a nivel español, pero esa modestia, tanto de superficie como de producción, se vuelve todo lo contrario desde el punto de vista comercial, lo que constituye un triple triunfo por sus precios elevados, por el tipo de producto que rompen con los tintos de mediana calidad, y, por último, por lo simbólico, carta maestra que lo sitúa como el producto de un terruño que supo salvaguardar su carácter genuino ante las mutaciones del mundo moderno, mientras absorbía todos los elementos positivos que éste le ofrece. La compenetración entre actividad vinícola y las referencias a la historia, a la tierra, a la cultura, son otros tantos sólidos argumentos de venta.

También la dimensión política y hasta ideológica, cuando se trata de afirmar la especificidad aragonesa frente a la invasora personalidad de la cercana Cataluña, vuelve a surgir en el fomento y la promoción de este viñedo: los grandes esfuerzos consagrados por el Gobierno autónomo para salvar la primera de las bodegas y para participar en la creación de algunas otras no obedecen solo a la lógica liberal.

Por otra parte, es imposible ocultar la corta edad del viñedo. Pero esta contradicción no perjudica en esa España de cambio de siglo, que se va integrando a marchas forzadas y con buena fortuna, tanto en la Unión Europea como en el sistema mundial. La España anterior al período de los años 80, la de la nueva derecha de los 90 , era la del franquismo agónico, hacia que el cuerpo social español se muestra bastante amnésico. El nuevo viñedo arraigado en la añeja tierra aragonesa se dirige a los espanoles acomodados de la nueva clase media-alta. Ese consumo corre parejo con la práctica de deportes de invierno, del golf o de regatas, con la renovación del parque de coches a favor de los de fuertes cilindradas o los 4 x 4, con el frecuentar restaurantes y clubs. 
Entre las ilustraciones del libro ya citado "Vinos de siglos en el Somontano de Barbastro" (Sabio-Alcutén, 2001) el desfase entre esos dos mundos se repite entre la foto del cura que echa agua bendita, en 1968, sobre las cubas de la primera vendimia de la Cooperativa (p. 193) y la de las instalaciones modernísimas de la sede del Consejo Regulador (p. 246 y 247). Los creadores del vino del Somontano tuvieron perfectamente en cuenta la mutación de España para asentar su comercialización.

En cuanto a la conquista de los mercados europeos, se explica tanto por los altísimos precios de los caldos bordeleses y borgoñones, como por la curiosidad y el eclecticismo enológicos que caracterizan a los europeos del norte, quizás porque no tienen viñas. El mercado británico, igual que para el Jerez o el Oporto desde el XIX, el coñac desde el XVIII, o incluso para los clarets bordeleses desde la Edad Media, sirve de locomotora para ese viñedo.

El producto del Somontano se parece, tanto por las técnicas enológicas como por las cepas empleadas, al de otros viñedos nuevos de España (Ribera del Duero, Bierzo) y de Europa (nuevos Corbières, Cahors rejuvenecido, Côtes du Rhône) y de nuevos mundos (Australia, Chile, Argentina). La diferencia está en los métodos de marketing y en el respectivo dinamismo comercial. Se nota en el Somontano el mismo espíritu de conquistador que anima a la economía española de los últimos veinte años. En relación con los grandes de la viña, el Somontano se queda en un nuevo viñedo cuyo renombre está por confirmar. Pero tiene ya ganada una imagen fuerte en España y en el suroeste francés, muy atraído por las sierras del Alto Aragón.

\subsection{El impacto económico en el Somontano}

El viñedo se hizo creador de empleo: En el sector primario emplea a 445 agricultores que tienen derecho a la Denominación y algunas decenas más. Las grandes bodegas tienen numerosos empleados, el Consejo Regulador unas diez personas. Dichos empleos inducen otros indirectos, llegando el total de personas que viven del viñedo a unas 1.000 , más o menos.

Esta actividad redunda en beneficio directo de Barbastro, pero también en Salas Bajas, cuya calle mayor se ha prolongado con media docena de casas nuevas, construidas por los empleados de la bodega vecina.

El volumen de negocio de las bodegas no es nada descleñable. En 2000 Pirineos realizó un volumen de negocios de 6,61 millones de euros (1.100 millones de pesetas), y Viñas del Vero de 12 millones de euros (2.000 millones de pesetas). Son las 
únicas cifras que conocemos. Entre los diferentes actores, el Gobierno autónomo de Aragón tuvo un papel decisivo, pero también los bancos aragoneses, la CAI sobre todo, reforzando el peso regional de la operación.

Finalmente, en cuanto a la imagen, si el viñedo se sirve de los paisajes, monumentos y terruños agrícolas del Somontano, en contrapartida es toda la región la que se adueña de la nueva denominación para afianzar su identidad y colocarse en el contexto aragonés, pirenaico y hasta español.

\section{Conclusión}

El Somontano es un viñedo integrado que se destina a abastecer un mercado con vinos de alta calidad. Ha supuesto una tajante ruptura con los caldos de autoconsumo de antaño, vendidos por los viticultores o, a granel, a los vinateros de la Rioja para cortar otros.

El vino así fabricado, totalmente nuevo, involucra la organización de la producción, provocando un nuevo modelado del campo. El Somontano constituye como una "burbuja" de producción que se sirve de Aragón -tierras, historia, cultura, nombre de lugares- para venderse mejor.

Se trata de una apuesta política y financiera. El Gobierno autónomo asumió un riesgo aportando capitales públicos, los bancos y empresarios invirtieron cuantiosamente y las participaciones cruzadas de las grandes bodegas hacen más solidarios a esos actores económicos con el éxito de la empresa.

Esas especulaciones corresponden a la demanda de un mercado español que se desarolla en paralelo al europeo, y hasta el mundial, en el que se cotiza ese tipo de vino que se ha vuelto universal. Hoy, la apuesta está ganada.

\section{Bibliografía}

Bielza de Ory, V. (1987): Geografia Humana de Aragón. Barcelona, Oikos-Taurus.

Consejo Regulador (2001): El vino de Somontano. Mecanografiado, $17 \mathrm{pp}$.
Daumas, M. (1976): La vie rurale dans le haut Aragon oriental. Saragosse, Departamento de Geogarafía Aplicada.

El País (1998): Sorbos nuevos en un viejo negocio. El Pais. 7 de junio de 1998. 
Estella, C. (1981): El viñedo en Aragón. Institución Fernando el Católico. Zaragoza.

Ferrer-Regales, M. (1957): El Campo de Cariñena. Tesis. Universidad de Zaragoza.

Heraldo de Aragón (1999): Entrevista a José Gracia Tarongi, presidente de SODIAR. Heraldo de Aragón. 19 de septiembre de 1999.

Higueras Arnal, A. (dir.) (1981): Geografia de Aragón. Zaragoza, (ver vol. 2).Guara.

Huetz de Lemps, A. (1967): Vignobles et vins du nord-ouest de l'Espagne. Thèse d'État. Université de Bordeaux.

Humbert, A. (1997): L'Espagne, Paris. Nathan-Université/Géographie d'aujourd'hui.
Milán del Bosch, I. (1995): Legislación básica sobre denominaciones de origen. Madrid, Tecnos.

Piqueras, J. (1988): Évolution récente et dynamique spatiale du vignoble espagnol. Méditerranée, p. 29-36.

Sabio-Alcutén, A. (2001): Vinos de siglos en el Somontano de Barbastro. Barbastro, Consejo Regulador.

Sindicato de Iniciativa y Propaganda de Aragón (S.I.P.A.) (1990): El iresistible ascenso del Somontano. Aragón turístico y monumental, $\mathrm{n}^{\circ} 336$, p. 31-33.

Viñedos y crianzas del alto Aragon (eds.) (2001): Enate: una bodega de nuestro tiempo. Vidéo-film. Ed. Viñedos y crianzas del alto Aragón.

Wais, F. (1974): Historia de los ferrocarriles españoles. Madrid, Editoria Nacional. 